\title{
OBITUARIO
}

\section{GERT GUENTHER HATSCHBACH}

(1923-2013)

\section{Curitiba decreta duelo por la muerte de Gert Hatschbach!}

Gert Guenther Hatschbach falleció en Curitiba, su ciudad natal, el 16 de abril de 2013, a los 89 años de edad, víctima de una infección generalizada. Había nacido el 22 de agosto de 1923 y llegó a ser uno de los más destacados botánicos de Brasil.

Se formó como Técnico en Química Industrial en 1945 en la Universidad Federal de Paraná, pero su inclinación por las ciencias naturales se manifestó mucho antes. Primero fue la entomología y luego la botánica, y en esta última su actividad tuvo reconocimiento mundial. A los 15 años comenzó a coleccionar Curculiónidos y al

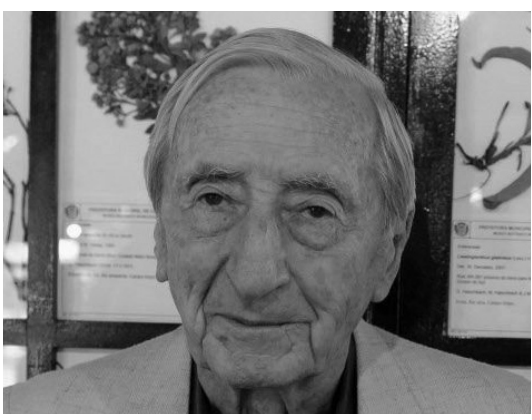
darse cuenta de que necesitaba conocer las plantas huésped comenzó a hacer su herbario y tomó gusto de ello.

Fue el fundador y director del Museo Botánico Municipal (MBM) en 1965, en una pequeña casa del Passeio Publico, ubicado actualmente en las dependencias del Jardín Botánico de Curitiba, institución donde desarrolló toda su actividad botánica. El acervo del museo fue iniciado con la colección de Calyptocarpus biaristatus en 1942, donde actualmente es el Parque Barigüi.

Fue un excelente herborizador, coleccionó más de 80.000 ejemplares, entre ellos cerca de 500 especies nuevas para la ciencia. Sabía elegir los lugares poco o nada explorados. Duplicados de sus colecciones los enviaba a especialistas de todo el mundo, por lo cual están muy bien distribuidos y a disposición de futuros estudios.

El herbario del Museo Botánico Municipal, el cuarto de Brasil, cuenta con más de 400.000 exsicatas reunidas durante su vida.

Recibió numerosos homenajes, 180 plantas llevan el nombre específico Gertii o Hatschbachii y le fueron dedicados dos géneros: Hatschbachia (Compuesta) y Hatschbachiellla (Gesneriácea). En zoología existe Gertia Hatschbachii, un coleóptero. También hay plantas dedicadas a María, su esposa y compañera de colecciones.

Una buena idea sobre sus aportes botánicos la da la publicación de KEW "Hatschbach's Paraná grasses" por S.A.Renvoize, 1988 (76 págs.).

En 1986 la Universidad Federal do Paraná le otorgó el título de Doctor Honoris Causa. En 2011 el Conselho Regional de Biología, Paraná e Santa Catarina (CRBio7) le concedió el título de Biólogo Honorario.

En 2012 recibió el título de Comendador da Orden do Pinheiro, concedido por el gobierno del Estado do Paraná.

En su aniversario de 89 años, en agosto de 2012, el museo organizó una exposición en su homenaje, en la que se mostraba la historia de vida y la trayectoria profesional del botánico.

Sus publicaciones se refieren principalmente a la flora de Paraná y aparecieron especialmente en el Boletim do Museu Botänico Municipal.

Además de ser un eximio botánico fue una excelente persona, muy querida y estimada por todo el mundo. Tuvimos con él una muy buena relación, tanto en el intercambio de material o de información, como en la participación conjunta de algunas expediciones botánicas.

En 1975 se casó con Maria Magdaura Hatschbach quién lo acompañó durante décadas en sus expediciones botánicas por todo Brasil y el exterior.

El Prefecto Gustavo Fruet decretó luto oficial durante tres días por la muerte de Gert, expresando así el sentimiento y el reconocimiento de su ciudad natal.

El Museo Botánico de Curitiba recibirá el nombre de su creador. 
